\title{
DNA Methylation: A Profile of Methods and Applications
}

BioTechniques 33:632-649 (September 2002)

\author{
Mario F. Fraga and \\ Manel Esteller \\ Spanish National Cancer \\ Research Center (CNIO), \\ Madrid, Spain
}

\section{INTRODUCTION}

Methylation of cytosines in the $5^{\prime}$ position of the pyrimidinic ring is the most important epigenetic alteration in eukaryotes. In animals, methylcytosine is mainly found in cytosine-guanine (CpG) dinucleotides (10), whereas in plants it is more frequently located in cytosine-any base-guanine $(\mathrm{CpNpG})$ trinucleotide sequences. The presence of 5-methylcytosine in the promoter of specific genes alters the binding of transcriptional factors and other proteins to DNA in plants (26) and animals (18). It also attracts methyl-DNA-binding proteins and histone deacetylases that modify chromatin structure around the gene transcription start site. Both mechanisms block transcription and cause gene silencing (10). Thus, methylation of $\mathrm{C}$ residues in genomic DNA plays a key role in the regulation of gene expression (99).

DNA methylation research can be approached from several standpoints because there is a wide range of techniques available for the study of the occurrence and localization of methylcytosine in the genome $(45,82,83)$. Each technique has its own peculiarities, which implies that there is a suitable technique for each specific problem. In any case, DNA methylation status can only be established by the joint use of various methodologies. Here we classify the available methods for studying the degree of DNA methylation, with respect to the type of information produced (Figure 1), including the degree of whole genomic DNA methylation, the DNA methylation status of a specific sequence, and how to find new methylation hot spots.

Levels of methylcytosine occurrence in the genomic DNA can be mea- sured by high-performance separation techniques or by enzymatic/chemical means. The latter are never as sensitive as the former, and sometimes their resolution is restricted to endonuclease cleavage sites. Despite the drawbacks, enzymatic/chemical approaches are still commonly used because, unlike separation techniques, they do not require expensive and complex equipment that is not always available. When separation devices are available, highperformance capillary electrophoresis (HPCE) may be the best choice since it is faster, cheaper, and more sensitive than HPLC (33). Although in situ hybridization methods for studying cytosine methylation status sometimes give accurate measures of the degree of total DNA methylation, one of the most interesting aspects of these approaches is that they provide information on tissuespecific methylation patterns. By means of labeled anti-methylcytosine antibodies, DNA methylation can be monitored in metaphase chromosomes, hetero/euchromatin, and, most importantly, on a cell-by-cell basis within the same sample. The latter alternative, which generally yields qualitative results, is of great interest in cancer research because it can reveal methylation differences between normal and tumor tissues in the same sample.

Two alternatives are currently used to study the degree of DNA methylation in particular DNA sequences: nonbisulfite and bisulfite methods. The first relies on the use of methylationsensitive restriction endonucleases combined with Southern blot analysis or PCR detection, which sometimes means that results are limited to cleavage sites. This problem can be avoided by the bisulfite modification of the DNA, which comprises a wide range of 
techniques that allow the quantitative and accurate determination of the methylation status of the allele, even at the cell population level. All bisulfiteassociated methods require PCR amplification of the bisulfite-modified DNA, and differences in methylcytosine patterns are displayed by methylation-dependent primer design (e.g., methylation-specific PCR), in conjunction with methylation-sensitive restriction endonucleases [e.g., combined bisulfite restriction analyses (COBRA)], genomic sequencing, and other approaches. Some of these approaches even provide quantitative data about the average proportion of methylated and unmethylated alleles in a population.

Thus, because of the large assortment of methods available for evaluating the degree of genomic DNA methylation and the wide range of data types they yield, the goal of this paper is to help researchers to choose the best method for addressing specific DNA methylation questions. To do this, we categorized the most important methods currently used by the type of information they provide. We also describe all the outstanding approaches and provide more detailed information about the techniques we consider most significant, discussing their advantages, disadvantages, and possible artifacts.

\section{QUANTIFICATION OF OVERALL METHYLCYTOSINE IN GENOMIC DNA}

Global DNA methylation has been proposed as a molecular marker for a variety of biological processes such as cancer $(32,76)$ and ontogenetic development in both plants (34) and animals (55). Methylcytosine concentration in genomic DNA is currently quantified by high-performance separation means (HPCE and HPLC) or by enzymatic/ chemical approaches.

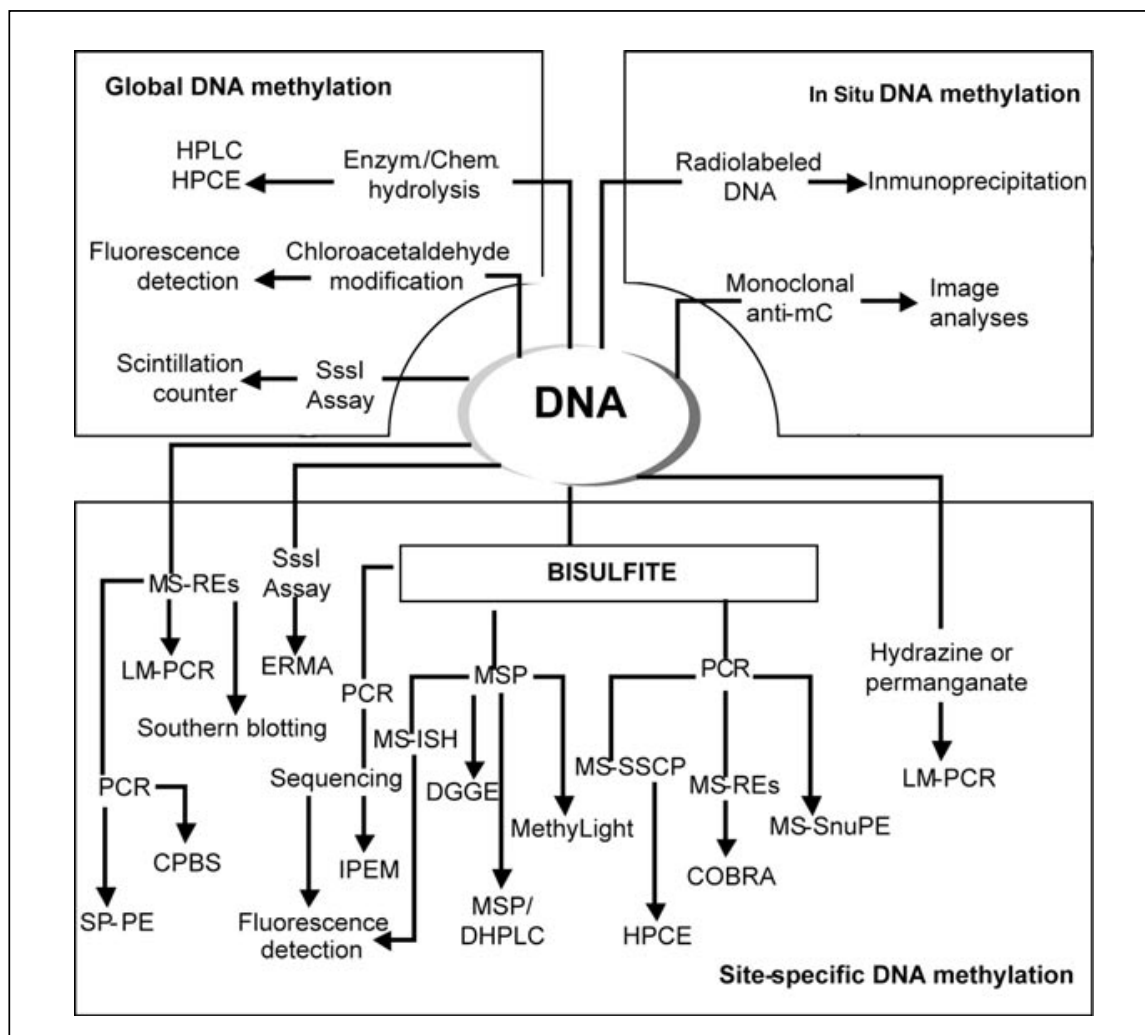

Figure 1. Main methods available for the study of genomic DNA methylation status. MSP, methylation-specific PCR; MS-SnuPE, methylation-sensitive single-nucleotide primer extension; MS-SSCP, methylation-sensitive single-stranded conformational polymorphism; MS-REs, methylation-sensitive restriction endonucleases; LM-PCR, ligation-mediated PCR; MS-ISH, methylation-specific in situ hybridization; IPEM, incomplete primer extension mixture; CPBS, competitive primer binding sites; SP-PE, solid-phase primer extension; and ERMA, enzymatic regional methylation assay.

\section{HPLC-Based Methods}

Relative methylcytosine contents of genomic DNA can be analyzed by chemical hydrolysis to obtain the total base composition of the genome and the subsequent fractionation and quantification of hydrolysis products using HPLC technologies. DNA hydrolysis can be carried out by incubation with formic acid at high temperature (27). However, Catania et al. (14) suggested the use of hydrofluoric acid for chemical hydrolysis of DNA to prevent deamination of cytosine and methylcytosine, which often occurs with formic acid.

In any case, enzymatic hydrolysis of the DNA is reported to be a better alternative for quantifying the degree of DNA methylation (58). The 2'-deoxymononucleosides are obtained using Nuclease P1, DNase I, and snake venom phosphodiesterase (25) or micrococcal nuclease and phosphodiesterase II (61), followed by hydrolysis with alkaline phosphatase. Resulting deoxyribonucleosides are subsequently separated by HPLC, and the methylcytosine levels are quantified by comparing the relative absorbance of cytosine and methylcytosine at $254 \mathrm{~nm}$ in the sample with external standards of known bases. The degree of DNA methylation of several animal (38) and plant tissues (98) has been quantified by this method, but at least $2.5 \mu \mathrm{g}$ DNA are generally required to quantify 5-methylcytosine with a low standard deviation for replicate samples. Moreover, this method suffers from occasional problems whereby elution buffers precipitate into the column (unpublished observation).

The sensitivity of the system can be increased with mass spectrometry detection, which has a detection limit $10^{6}$ times the limit of absorption spectroscopy detectors. Annan et al. (3) used HPLC-mass spectrometry coupled via a moving-belt interface to analyze electrophoretic derivatives of methylcytosine and 5-hydroxymethyluracil nucleobases. As little as $9.9 \mathrm{pg}$ (signalto-noise ratio, 5) and $180 \mathrm{fg}$ (signal-tonoise ratio, 10) of the respective nucleobases were detected in the negative electron-capture chemical ionization mode, and linear responses were observed over a moderate dynamic range. Alternatively, Gowher et al. (44) have 
developed a highly specific and sensitive assay for detecting trace amounts of methylcytosine in genomic DNA. They degraded DNA to nucleosides, purified methylcytosine by HPLC, and, for detection by 1-D and 2-D thin-layer chromatography (TLC), radiolabeled using deoxynucleoside kinase and $\gamma$ [32P]ATP. Using this assay, they showed that methylcytosine occurs in the DNA of Drosophila melanogaster at a level of 1 in 1000-2000 cytosine residues in adult flies. This labeling strategy has already been used to quantify methylcytosine concentration (61), but, in this case, it was employed in conjunction with 1-D high-performance TLC using alkylamino-modified silica plates.

\section{HPCE-Based Methods}

The development of CE techniques has given rise to an approach to research that has several advantages over current methodologies used to quantify the extent of DNA methylation. From its beginnings, CE has proved to be extremely helpful in separating various DNA components, including a number of base adducts (71), and recently Fraga et al. (33) have reported the quantification of the relative methylcytosine content of the genomic DNA of plants using a HPCE system to analyze acid-hydrolyzed genomic DNA. In this context, the separation and quantification of cytosine and methylcytosine are only possible by the use of an SDS micelle system. This method is faster than HPLC (taking less than $10 \mathrm{~min} / \mathrm{sample}$ ), reasonably inexpensive because it does not require continuous running buffers, and displays a great potential for fractionation (theoretically up to $10^{6}$ plates). Nevertheless, almost no preparative analyses are possible with HPCE systems because of the low injection volumes involved.

The release of bases from DNA by chemical means involves the production of a complicated mixture of molecules that makes the detection and quantification of methylcytosine difficult when DNA is not sufficiently purified and/or concentrated. This problem can be avoided by enzymatic hydrolysis with Nuclease P1 and alkaline phosphatase to produce 2'-deoxymononucleosides, which are then fractionated using a modification of the previously described HPCE method (33). Approximately one methylcytosine in 200 cytosine residues can be detected by this method using 1 $\mu \mathrm{g}$ genomic DNA (Figure 2). To increase sensitivity, laser-induced fluorescence and mass spectrometry detectors should be used. However, there are no references describing how to quantify methylcytosine. Nevertheless, capillary electrophoretic separation and online detection by monitoring laser-induced fluorescence have already been applied successfully to quantify other modified bases in DNA (100). Using laser-induced fluorescence monitoring systems, a concentration detection limit of approximately $3 \times 10^{-10} \mathrm{M}(91)$ or 1 adduct $/ 10^{7}$ normal nucleotides/ $\mu \mathrm{g}$ DNA (85) can be achieved.

\section{Analyses of Genome-Wide Methylation by Chemical or Enzymatic Means}

As stated earlier, quantifying the degree of DNA methylation by HPLC or HPCE requires access to sophisticated equipment that is not always available. The radioactive labeling of $\mathrm{CpG}$ sites using the methyl-acceptor assay (101) has been developed to address this problem, but, among the technique's other drawbacks, it can only monitor $\mathrm{CpG}$ methylation changes, thus $\mathrm{CpNpG}$ methylation cannot be detected. This method uses bacterial SssI DNA methyltransferase to transfer tritium-labeled methyl groups from S-adenosylmethionine (SAM) to unmethylated cytosines

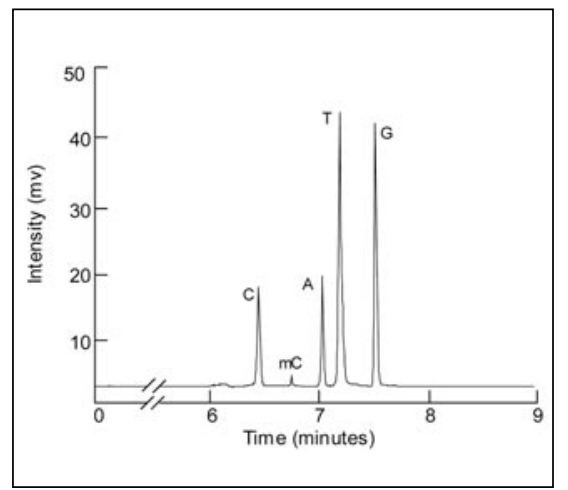

Figure 2. Resolution of nucleosides obtained from enzymatic hydrolysis of genomic DNA from human cancer cell line HT29 by HPCE. mC, 5-methylcytidine; A, adenosine; C, cytidine; $\mathrm{G}$, guanosine; and $\mathrm{T}$, thymidine. 
in $\mathrm{CpG}$ targets. The data obtained from a scintillation counter are used to calculate the number of methyl groups incorporated in the DNA. The amount of tritium incorporated is inversely proportional to the level of $\mathrm{CpG}$ methylation (23). This method has revealed changes in the DNA methylation patterns of patients who suffer from a number of diseases, including cancer (40).

Recently, a modification of the SssI assay was reported to allow the quantification of the degree of DNA methylation in specific DNA regions (37). This quantitative approach, termed enzymatic regional methylation assay (ERMA), provides high-quality information about the methylation density of a sequence. However, as in the previously described case of the SssI assay, the acquisition of data is limited to specific endonuclease cleavage sites. The method merges bisulfite modification of DNA and PCR amplification of the region of interest with $S s s \mathrm{I}$ and ${ }^{3} \mathrm{H}-\mathrm{la}-$ beled SAM incubation using dam methyltransferase and ${ }^{14} \mathrm{C}$-labeled SAM as an internal control [primers for PCR are designed to contain two dam sites (CATG)]. Under this combination of conditions, the relative ${ }^{3} \mathrm{H} /{ }^{14} \mathrm{C}$ signal ratio is linearly correlated with the methylation density of the region of interest. In general, methods based on the acceptance of methyl groups in vitro can give inaccurate but reproducible results. If these methods are used, then they should be validated on a few samples with a direct quantitative analysis for global 5-methylcytosine levels.

Combining the sodium bisulfite reaction with the ability of chloroacetaldehyde to label DNA fluorescently, Oakeley et al. (74) described a method for analyzing DNA methylation in any sequence by fluorescent labeling. They treated the DNA with chloroacetaldehyde, which reacts quantitatively with cytosine and adenine bases to yield the fluorescent adducts ethenocytosine and ethenoadenine, respectively, while uracil, thymine, and guanine do not undergo this reaction. Following DNA depurination, the extent of fluorescence as quantified with a luminescence spectrometer is proportional to the amount of methylcytosine in the genome. This method has several advantages over the methyl-acceptor assay: a chemical, rather than an enzymatic reaction, used quite stable and inexpensive reagents, and its measurements are not restricted to the methylcytosine located in $\mathrm{GpC}$ targets.

Diaz-Sala et al. (22) described other approaches in plant samples. They were able to measure the relative degree of DNA methylation accurately by the fluorescence quantification of the online slab of DNA digestion products that were obtained with methylationsensitive endonucleases. 


\section{In Situ Hybridization Methods for Studying Total Cytosine Methylation}

Global DNA methylation can also be quantified by methylcytosine-specific antibodies (67). The accessibility of methylcytosine to specific antibodies in dsDNA was first reported in the mid1980s (2). An outstanding advantage of this approach is that it may be carried out on a cell-by-cell basis rather than in a heterogeneous population. Every in situ hybridization-based technique for the study of DNA methylation must be previously validated with a control for the accessibility of the antibody to the DNA.

Classical immunoassay detection approaches involve quantifying the retention of radiolabeled DNA by polyclonal antibodies on nitrocellulose filters, immunoprecipitation, gel filtration, and visualization under electron microscopy (2). Cytosine methylation can also be detected in metaphase chromo- somes $(4,70)$ and in chromatin using monoclonal antibodies (MAbs) combined with fluorescence staining (68). The incorporation of 5-bromodeoxyuridine in DNA with a thermal denaturation step may increase the binding efficiency of anti-methylcytosine antibodies on metaphase chromosomes and increase the efficiency of antibody binding, as revealed by immunofluorescence staining (70). As a result of differential immunofluorescence staining, this method allows the semi-quantitative analysis of the antibody binding sites in metaphase chromosomes. Furthermore, in situ hybridization with fluorescence detection makes it possible to distinguish different methylcytosine-rich DNA sites (4). For example, secondary constrictions, juxtacentromeric regions, and T-bands emit strong fluorescence, while the short arms of acrocentrics produce strong polymorphic signals.

Quantitative in situ DNA methylation immunofluorescence analyses can be accomplished using an image analyzer and a charge-coupled device camera (97). For this purpose, sample results must be compared with results obtained from cells with known methylation levels. The study of global DNA methylation of human female $\mathrm{X}$ chromosomes using this method revealed global hypomethylation of the late-replicating $\mathrm{X}$. In addition, there is a method that allows not only the mapping of structural (banding) but also functional (methylation status) features of different chromosome domains (6). This strategy uses MAbs on mildly denatured chromosomes. An alternative to fluorescence detection is to connect a colored enzyme-dependent reaction. For instance, peroxidase-tagged second antibodies, with 4-chloro-1-naphthol used as substrate with anti-5-methylcytosine MAbs, have been used to quantify the effects of the demethylating agent 5-azacytidine 
on the constitutive heterochromatin of human chromosomes (21).

When comparing the results of global DNA methylation evaluated by the radiolabeled methyl incorporation assay (an alternative method for the quantification of global DNA methylation levels) (19) with immunohistochemical staining of the same tissue sections with MAbs against methylcytosine, similar contents are generally observed. In addition, in situ hybridization can also reveal differences in the methylation status of cancer and normal adjacent tissues by analyzing the same tissue section.

Because of the high sensitivity and specificity required, antibody design and production must be carefully considered, even though these topics depend on the detection method. One of the highest sensitivities (in the pmol range) can be achieved by the FMC9 $\mathrm{MAb}$ in conjunction with an ELISA
(69). This MAb displays excellent specificity because it reacts with methylcytidine and methylcytosine but not with other nucleosides. When sufficient specificity is achieved and no cross-reactions are detected, in situ DNA methylation immunofluorescence analyses can be used to monitor significant growth processes in animals [e.g., embryo development (11)] and plants [e.g., pollen nuclei maturation (73)].

\section{NON-BISULFITE METHODS FOR MAPPING METHYLCYTOSINES IN SPECIFIC DNA SEQUENCES}

The most widely used methods for studying DNA methylation patterns of specific regions of DNA with no base modifications are based on the use of methylation-sensitive and insensitive restriction endonucleases (15). One of the restriction enzymes of the iso- schizomer pair is able to cut the DNA only when its target is unmethylated, whereas the other is not sensitive to methylated cytosines. The most common isoschizomers used are the HpaII/ MspI pair. In general, both cleave the DNA at the CCGG target, but HpaII is not able to cut when the second cytosine is methylated (CmCGG). Moreover, it was reported that cleavage by MspI of GGCCGG sequences is also inhibited by the methylation of the $\mathrm{C}$ next to the CpG (12). EcoRII/BstNI isoschizomers are more frequently used in plants, whereas most methylcytosine is located at CCNGG sequences (where $\mathrm{N}$ is any base other than G) (46). EcoRII recognizes CCNGG targets, but it only cleaves when unmethylated (9), whereas $B s t$ NI is insensitive to cytosine methylation. Although these pairs of enzymes can cleave hemimethylated DNA, they do not distinguish between cytosines methylated at different posi- 
tions in the pyrimidinic ring (13). However, there are several restriction enzymes that recognize the localization of the methyl group (64).

Once DNA has been digested with methylation-sensitive endonucleases, identification of the methylation status of a gene can be accomplished by Southern blot hybridization or PCR procedures (Figure 3 ). In the first case, digestion products are separated by gel electrophoresis, transferred to a nitrocellulose filter, and hybridized with a radiolabeled probe (63). When DNA digestion is accomplished by methylation-sensitive nucleases, obtaining a DNA fragment that is larger than expected indicates methylation at one or both restriction targets that flank the homologous region of the DNA (Figure $3)$. An methylcytosine-positive will be detected when at least $10 \%$ of the DNA present that modification because of their hybridization sensitivity.

When the amount of tissue is limiting, detection of cytosine methylation can be achieved by PCR, which requires less than 10 ng DNA, whereas Southern blot hybridization generally requires up to $10 \mu \mathrm{g}$ DNA. Furthermore, a methylcytosine-positive can be detected when only $0.1 \%$ of the DNA molecules present such base modification (60). PCR primers must correspond to flanking sequences of the restriction targets so that the absence of methylation is revealed in the presence of a PCR band (Figure 3) (87).

For quantitative analyses, Heiskanen et al. (50) described a solid-phase quantitative primer extension method that can be adapted to a microtitration well format, thereby allowing the analysis of a large series of samples. In particular, the method produces linearity in a range from $2 \%$ to $100 \%$ of malignant blasts diluted with normal leukocytes. Quantitative PCR can also be performed by a modification (88) of the method described by Singer-Sam et al. (87). The improvement, termed competitive primer binding sites, includes an internal standard sharing primer-binding sites with the genomic template so that demethylation results in a decrease of the PCR products. Nevertheless, a comparison of the samples entails the accurate quantification of the amount of DNA, which is commonly a difficult task when such small amounts of DNA are handled. There is another method that consists of measuring the conversion of a large amplified DNA fragment to a shorter DNA product that correlates with the amount of demethylation (65). The procedure uses pairs of nonisoschizomeric enzymes to cleave genomic DNA at closely spaced sites. The extent of cleavage by the methylationsensitive restriction enzyme is quanti- fied by the amplification of the digestion products with ligation-mediated PCR and radioactive labeling. The ratio of the two amplified fragments correlates with the degree of methylation at the restriction site.

PCR methods involving prior digestion with $\mathrm{CpG}$ methylation-sensitive restriction endonucleases can be complicated by the inability to achieve $100 \%$ digestion of the sensitive sites, even

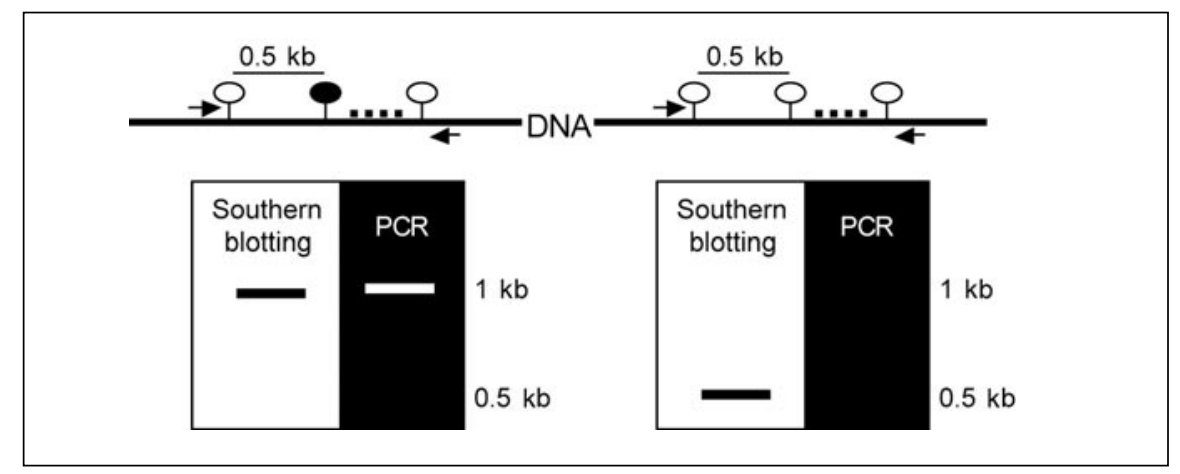

Figure 3. Anticipated results when studying site-specific DNA methylation by Southern blot analysis and PCR (two of the most important non-bisulfite-related methods) in the cases of methylation and unmethylation for a single CpG target. Black circles indicate cytosine methylation. Arrows symbolize PCR primers. The discontinuous lines illustrate probes for Southern blot analysis.

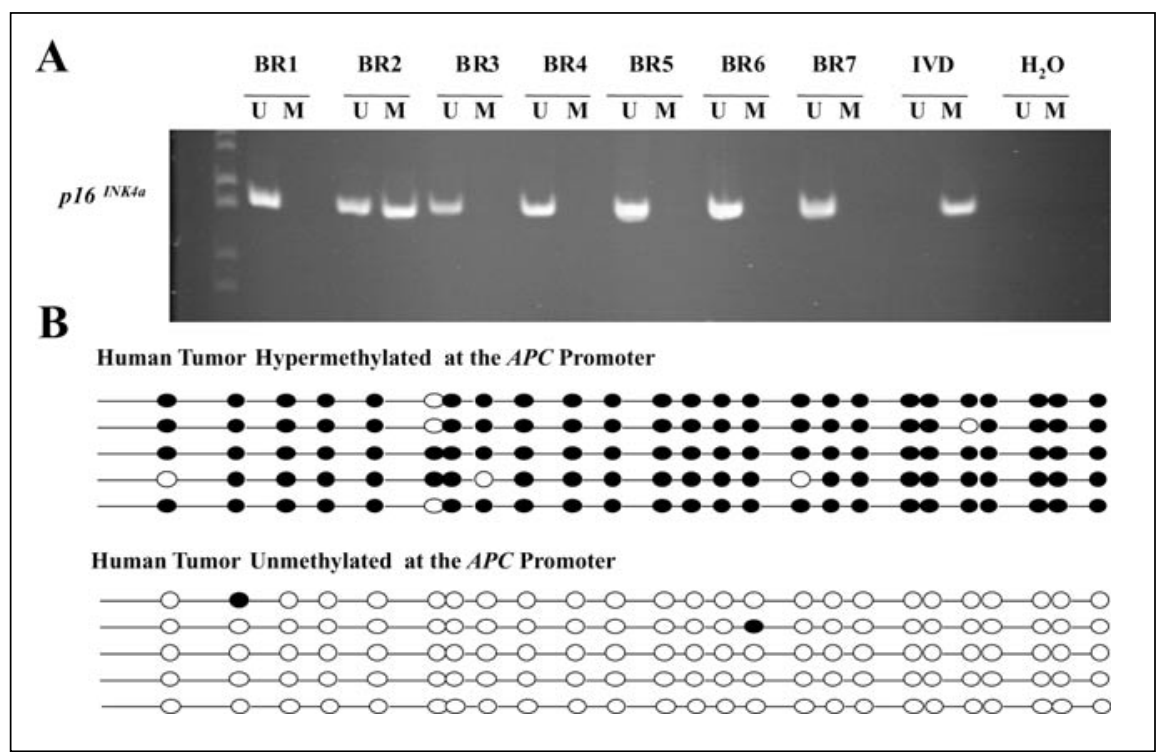

Figure 4. Methylation-specific PCR and bisulfate sequencing. (A) Methylation status of the $p 16^{I N K 4 a}$ $\mathrm{CpG}$ island in human primary breast tumors determined by methylation-specific PCR. PBR322/Msp digest (New England Biolabs, Beverly, MA, USA) is shown at left as the molecular weight marker. The presence of a visible PCR product in the lanes marked U indicates the presence of unmethylated genes, and the presence of PCR product in the lanes marked M indicates the presence of methylated genes. In vitro methylated DNA was used as a positive control for methylation, normal lymphocytes were used as a negative control for methylation, and water was used as a negative PCR control. The breast tumor BR2 is hypermethylated at P16, while the remaining tumors (BR1, BR3, BR4, BR5, BR6, and BR7) are unmethylated. (B) Graphical representation of the sodium bisulfite genomic sequencing of the $\mathrm{CpG}$ island of the $A P C$ promoter. Each row represents an individual cloned and sequenced allele after sodium bisulfite DNA modification. $\mathrm{CpG}$ sites are shown as circles and drawn to accurately reflect $\mathrm{CpG}$ density of the region. White dots are unmethylated CpGs, and black dots are methylated CpGs. IVD, in vitro methylated DNA. 
with multiple rounds of digestion using high concentrations of enzyme. Although PCR can amplify even a single target DNA molecule when sufficient rounds of amplification are employed, misleading results can be obtained with such methods if adequate controls are not used. This is why cleavage with a restriction isoschizomer of the methylation-sensitive endonuclease is a commonly used control (95). Even though partially cleavage-resistant sites have been commonly interpreted as being partially methylated, the importance of the intrinsic resistance to cleavage of certain DNA targets should be stressed (59). This resistance can be overcome by the addition of site-containing oligonucleotide duplexes that drive the cleavage of the resistant sites.

Non-bisulfite methods for the quantification of DNA methylation patterns are simple, rapid, and can be used for any known-sequence genomic DNA region. These methods are extremely specific, but their limitation to specific restriction sites reduces their value.

\section{BISULFITE METHODS FOR MAPPING METHYLCYTOSINES IN SPECIFIC DNA SEQUENCES}

Although isoschizomer-based methods for the study of methycytosine occurrence at specific DNA regions display high sensitivity, they cannot provide the critical information required for a complete understanding of the role of methylcytosine in cell and molecular biology. These aspects can be addressed with the bisulfite modification of the DNA (17).

There is an extensive range of methods for the quantification of the methylation status of cytosines located in specific DNA regions based on the sodium bisulfite treatment (Figure 1). Bisulfite converts unmethylated cytosine to uracil, while methylated cytosine does not react (36). This reaction constitutes the basis for discriminating between methylated and unmethylated DNA. Bisulfite transformation of DNA can be followed by several methods, including sequencing, methylation-specific PCR, combined bisulfite restriction assays, and others. In general, each modification leads to greater sensitivity and res- olution or contributes to the development of a novel perspective on the results. All of them work with PCR, which, among other advantages, is suitable for analyzing paraffin-embedded tissues and poorly purified DNA.

Bisulfite modification of DNA requires prior DNA denaturation because only methylcytosines that are located in single strands are susceptible to attack (84). The partial denaturation of the DNA is a common event that causes one of the potential artifacts of the method. Renaturation induced by high-salt concentrations could be an additional critical problem, although bisulfite is generally able to react with the DNA before renaturation occurs. Nevertheless, false positives caused by the lack of the single-stranded conformation have been reported (81). Incomplete desulfonation after bisulfite treatment may also give rise to several problems (93). The presence of residual bisulfite can avert the adequate alkalization of the solution so that, if the $\mathrm{pH}$ is lower than nine, the rate of pyrimidine desulfonation is rather slow, thereby rendering certain DNA polymerases incapable of replicating the template. However, the problem may be avoided by measuring the $\mathrm{pH}$ after the alkalization step.

It was originally believed that all the cytosines in densely methylated regions in the chromosome replication origins were methylated (92), but methylation at non-CpG residues was later discovered to be an artifact of partial bisulfite conversion. Harrison et al. (48) attempted to explain this observation by suggesting that a methylated cytosine could protect the neighboring unmethylated outer cytosine from complete bisulfite conversion and that this is a sequencespecific event. They also suggested that the problem could be avoided by using an internal standard that consists of checking the complete bisulfite conver- 
sion of a non-CpG site from an in vitro synthetic methylated oligonucleotide.

As previously stated, the total conversion of cytosines to uracils is critical to the success of the analyses. The maximum conversion rates of cytosine occur at $55^{\circ} \mathrm{C}(4-18 \mathrm{~h})$ and $95^{\circ} \mathrm{C}(1 \mathrm{~h})$. Special attention must be paid to the influence of the temperature and incubation time on DNA integrity during the bisulfite treatment because, under these conditions, $84 \%-96 \%$ of the DNA is degraded (47). Raizis et al. (80) also reported the occurrence of partial DNA degradation during bisulfite treatment, but in their case, it was due to low $\mathrm{pH}$ dependent depurination. A simple solution to limit the degradation of the DNA template is provided by the authors, who suggest reducing the time required to complete the bisulfite reaction by means of increasing the bisulfite concentration to $5 \mathrm{M}$. Under these conditions, optimal PCR production occurs after only $4 \mathrm{~h}$, thereby minimizing DNA fragmentation.

\section{Sequencing}

Sequencing bisulfite-altered DNA is the most straightforward means of detecting cytosine methylation. In general, after the denaturation and bisulfite modification, dsDNA is obtained by primer extension, and the fragment of interest is amplified by PCR (17). Methylcytosine can then be detected by standard DNA sequencing of the PCR products (Figure 4B). Cloning PCR products into plasmid vectors followed by the sequencing of individual clones is an alternative method that, although slower, could provide methylation maps of single DNA molecules, instead of the average values of the methylation status in the population of molecules provided by direct sequencing of the PCR products. This approach has been helpful in the study of the DNA methylation of genes associated with cancer such as APC (30) and Rb (89).

Consistent quantification of cytosine methylation by direct sequencing has been widely reported to entail the means of fluorescence-based detection (78). Paul and Clark (75) described a method of automated genomic sequencing with fluorescence detection (GENESCAN; GeneScan Australia Pty.
Ltd., Bundoora, Australia) that provides a measure of the degree of methylation at a particular target by comparing cytosine and thymine signals that have been labeled with the same fluorescent dyes. This method has been used to examine the detailed methylation state of many $\mathrm{CpG}$ island-containing genes in cancer (66). Moreover, Radlinska et al. (79) described an alternative method that allows the direct localization of methylcytosines in the primary product of the bisulfite treatment instead of the PCR amplification product. To achieve this, they used a primer extension mixture containing only three deoxynucleotides (dATP, dCTP, and dTTP) and lacking dGTP (IPEM) that produced an elongation stop at methylcytosine points. The positions of the methylcytosine are recognized by comparing the localization of runoff products to products of sequencing reactions performed on bisulfite-untreated template DNA. The method, which gave no false-positive results at all, has a sensitivity of 4-7 ng (50 fmol of the methylated sites).

Normally, four termination reactions

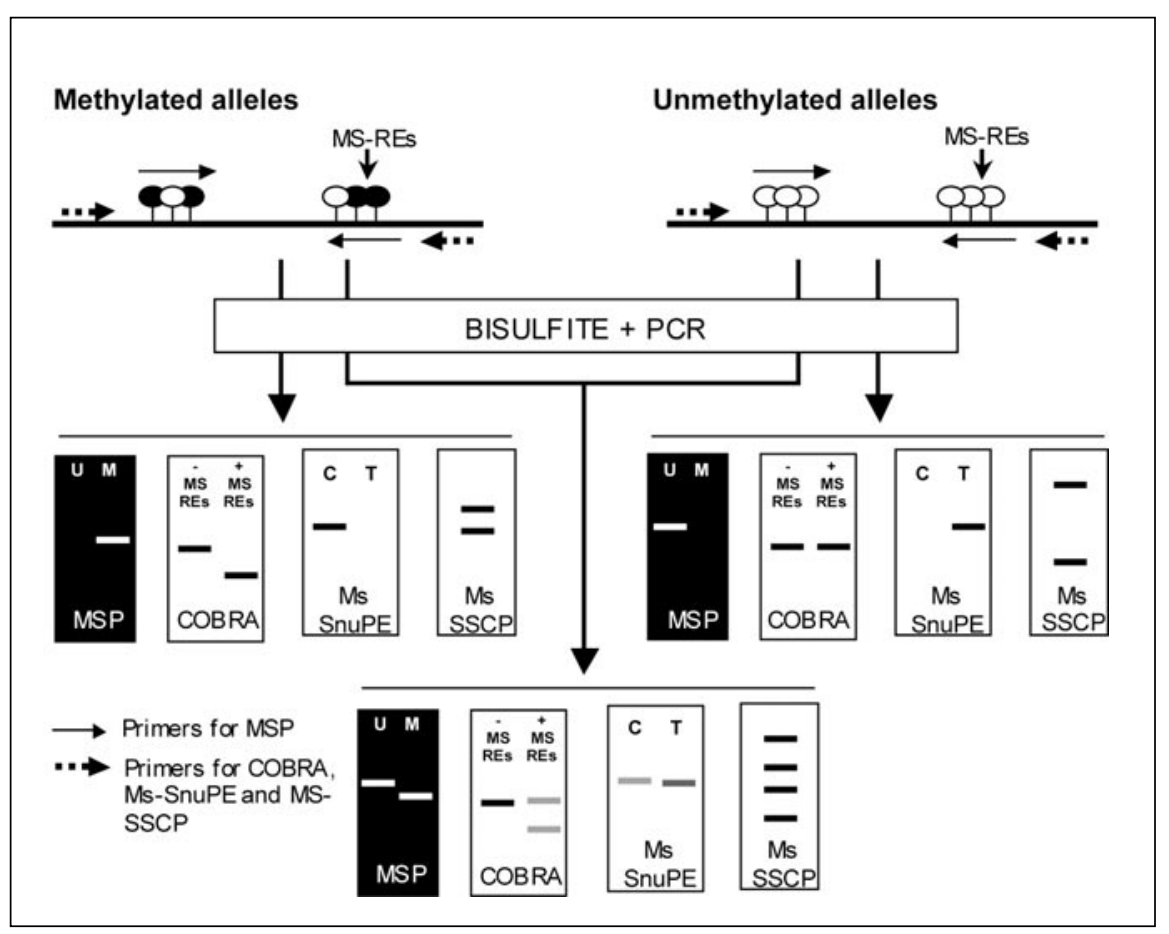

Figure 5. Methylation results for methylated, unmethylated, and mixtures of methylated/unmethylated alleles obtained by several bisulfite-related methods. MSP, methylation-specific PCR; MsSnuPE, methylation-sensitive single nucleotide primer extension; Ms-SSCP, methylation-sensitive single-stranded conformational polymorphism; MS-REs, methylation-sensitive restriction endonucleases; $\mathrm{U}$, unmethylated reaction; $\mathrm{M}$, methylated reaction; $\mathrm{C}$, cytosine band; and $\mathrm{T}$, thymine band. Black circles indicate cytosine methylation. were set up to display methylcytosine occurrence by the sequencing method, but only one termination reaction is needed when the sequence of the target region is known (103). The choice of termination reaction depends on the type of base conversion for which the sequencing primers are designed, and the results are obtained by comparing products of the single termination reaction to those of normal sequencing terminations from the control unmodified DNA.

\section{Methylation-Specific PCR}

Methylation-specific PCR is the most widely used technique for studying the methylation of $\mathrm{CpG}$ islands, which are common in the promoter regions of many genes. Cytosines in $\mathrm{CpG}$ islands are usually unmethylated in normal tissues, whereas they become methylated in the promoter sequences of genes associated with certain abnormal cellular processes such as cancer (31). Methylation-specific PCR (51) is one of the most effective choices for investigating the methylation profile of 
these regions $(28,31,32)$.

The differences between methylated and unmethylated alleles that arise from sodium bisulfite treatment are the basis of methylation-specific PCR (Figure 5) and are especially valuable in $\mathrm{CpG}$ islands because of the abundance of $\mathrm{CpG}$ sites. Primer design is a critical and complex component of the procedure (Figure 5). Bisulfite-converted DNA strands are no longer complementary, so primer design must be customized for each DNA chain. Methylation patterns of all sequences must be determined in separate reactions (Figure 4A). To optimize the PCR amplification step, the following critical requirements must be considered when designing the primers: $(i)$ the annealing temperature of both primers must be similar and always between $55^{\circ} \mathrm{C}$ and $65^{\circ} \mathrm{C}$; (ii) the PCR product should be between 80 and $175 \mathrm{bp}$; (iii) each primer should contain at least two CpG pairs; (iv) the sense primer should contain a $\mathrm{CpG}$ pair at its $3^{\prime}$-end; and $(v)$, to avoid false positives (amplification of unmethylated, unmodified DNA), primers should contain non-CpG cytosines.

The great sensitivity of the method allows the methylation status of small samples of DNA, including those from paraffin-embedded or microdissected tissues (51). However, resolution at the nucleotide level requires the sequencing of the PCR products, and quantitative data and identification of cellular heterogeneity in populations are still not possible with this technique. If the PCR involves too many cycles of amplification without ensuring that the reaction is in the linear response range with respect to the template concentration, then large overestimates of the extent of methylation can be obtained if the sequence is amplifiable with both the methylation-specific primers and the primers for the unmethylated sequence. In addition, the appropriate control DNA sequences should have been shown first to give no PCR product with the methylation-specific primers. The conclusion about methylation could refer to only a small percentage of the examined cells in the population unless the PCR is done semi-quantitatively, varying the template concentration or cycle number, and the efficiency of the methylation- specific primers and the primers for the unmethylated sequences has been compared. Non-quantitative, methylationspecific PCR results can be validated with a quantitative method on some of the samples (e.g., Southern blot analysis with a $\mathrm{CpG}$ methylation-sensitive restriction endonuclease). With previously unused primers, unmethylated and in vitro methylated control sequences should be tested.

To avoid such problems, Nuovo et al. (72) made a remarkable advance in the method by combining methylation-specific PCR with in situ hybridization. The modification allows for the methylation status of specific DNA sequences to be visualized in individual cells. This powerful approach is mainly used to monitor methylation patterns in sample tissues with complex mixtures of tumor-like and normal cells. Another method that was recently described combines methylation-specific PCR and denaturing HPLC (DHPLC), with which even small cell mosaicisms of structurally normal and/or abnormal chromosomes can be detected (5). Following PCR amplification, the alleles can be resolved from the two populations of PCR products by DHPLC because they differ at several positions within the amplified sequence. Distinct clonotypic epigenotypes can also be isolated and characterized by denaturing gradient gel electrophoresis (DGGE) (1), which allows the detection of almost any sequence change in every DNA region, including differentially methylated sequences.

Another quantitative approach is called MethyLight (24), which uses fluorescence-based, real-time PCR technology and does not involve additional PCR steps. The DNA is modified by the bisulfite treatment and amplified by fluorescence-based, real-time quantitative PCR using locus-specific PCR primers that flank an oligonucleotide probe with a $5^{\prime}$ fluorescence reporter dye and a $3^{\prime}$ quencher dye. The reporter is enzymatically released during the reaction, and fluorescence, which is proportional to the amount of PCR product and thus to the degree of DNA methylation, can be sequentially detected in an automated nucleotide sequencer device. Fluorescence detection greatly increases the sensitivity of the method, 
making it possible to detect a single methylated allele in $10^{5}$ unmethylated alleles. However, the major advantage is that sequence discrimination can be achieved at any level of probe hybridization or PCR amplification as a result of the particular primer design. The quantitative nature of the assay is based on real-time PCR and the inclusion of a methylated reference DNA. This assay allows the comparison of normal tissue samples with low levels of methylation at the test sequences and tumors with significantly more methylation. It also allows the quantitative assessment of DNA methylation at specific sequences with high throughput, permitting the rapid analysis of many DNA samples at many different sites.

Because of the versatility of the method, methylation-specific PCR has been widely proposed as a rapid and cost-effective clinical tool to use in the initial evaluation of a wide range of patients with specific allele-dependent diseases. For instance, methylationspecific PCR is currently applied to evaluate the methylation status of the $\mathrm{CpG}$ island of the SNRPN gene and, hence, for the rapid diagnosis of the Prader-Willi and Angelman syndromes (57). This approach also provides an accurate assay for the determination of $\mathrm{X}$ inactivation and can be carried out on DNA samples that are unsuitable for restriction digestion. Incidentally, these are the most widely used means to evaluate the methylation status in active and inactive $\mathrm{X}$ chromosomes. Uchida et al. (96) described a slight modification of this method, which they called human androgen-receptor gene-methylation-specific PCR (HUMARA-MSP). This involves the analysis of the $\mathrm{X}$ chromosome inactivation pattern by an optimized methylation-specific PCR method that can identify the average proportions of methylated and unmethylated alleles through the examination of a polymorphic short tandem repeat near the $5^{\prime}$ promoter region.

Methylation-specific PCR has also been successfully used to evaluate the responsiveness of human cancer patients to alkylating agents. By using methylation-specific PCR, Esteller et al. (29) found hypermethylation of the DNA-repair enzyme MGMT to be a key factor in the resistance to alkylating agents. This involves tumor regression because of the increase of the responsiveness to alkylating agents caused by the lack of MGMT. Methylation-specific PCR has also been useful in the detection of the presence of tumoral DNA in the serum of cancer patients (41).

\section{COBRA}

COBRA (102) constitutes a highly specific approach releasing on the creation or detection of a target for restriction endonuclease after bisulfite treatment. The major advantage of this method is that it provides semi-quantitative data regarding the methylation status at specific regions in any DNA sample (Figure 5).

DNA amplification products of specific loci, previously modified by bisulfite, are digested with restriction enzymes that distinguish methylated from unmethylated sequences so that the degree of DNA methylation is linearly correlated with the relative amounts of digested and undigested products. The $B s t \mathrm{UI}$ case may illustrate this point; its cleavage site (CGCG) is resistant to bisulfite modification when it is methylated but is transformed to TGTG when it is unmethylated. Thus, DNA cleavage after bisulfite treatment only occurs if the restriction target is methylated and the cleavage products are proportional to the degree of methylation of the analyzed sequence. The average relative proportions of digestion products can be quantified by hybridization with $5^{\prime}$-endlabeled oligonucleotides and phosphorimager detection. In contrast to methylation-specific PCR, the PCR primers should not contain $\mathrm{CpG}$ pairs to avoid discrimination between different methylated templates. In general, this approach can be used when absolute percentages of methylated and unmethylated alleles are required to guarantee the final diagnosis. The major drawback is that $B s t \mathrm{UI}$ will also cut if unconverted; therefore, the use of this enzyme can lead to the overestimation of methylation. Monitoring conversion state with enzymes such as HpaII is needed (54).

Although it is specific, quantitative, and sensitive, this approach entails complete bisulfite modification and cannot be used for all DNA sequences because it is confined to restriction targets.

\section{Methylation-Sensitive Single Nucleotide Primer Extension}

Methylation-sensitive single nucleotide primer extension employs bisulfite-PCR combined with single nucleotide primer extension to analyze DNA methylation status quantitatively at a particular DNA region without using restriction enzymes (Figure 5). This allows the analysis of almost all DNA regions (42). In this approach, the incorporation of $\mathrm{C}$ instead of $\mathrm{T}$ results in methylation in the original DNA sequence (Figure 5).

Following the bisulfite modification of the whole genomic DNA, the region of interest is amplified by PCR techniques, using primers specifically designed for the new bisulfite-modified sequence of DNA. PCR-generated products are also amplified using internal primers that terminate immediately $5^{\prime}$ of the single nucleotide to be assayed. The relative average amount of allele methylation is quantified by monitoring the incorporation of both $\left[{ }^{32} \mathrm{P}\right] \mathrm{dCTPs}$ and $\left.{ }^{32} \mathrm{P}\right] \mathrm{dTTPs}$ using a phosphorimaging device. Under these conditions, the intensities of bands in the $\mathrm{C}$ tracks are proportional to the average amount of methylation at each tested $\mathrm{CpG}$ site. Meanwhile, the intensity of the $\mathrm{T}$ tracks is linearly correlated with the percentage of unmethylated cytosines.

Similar to other quantitative bisulfite-PCR methods, methylation-sensitive single nucleotide extension has a broad range of clinical applications because of its high sensitivity, specificity, and requirement for only small amounts of sample. Despite all of these advantages, PCR bias and analyses in CpG-rich regions can be a problem because of the difficulty of successfully designing primers lacking $\mathrm{CpG}$ dinuclotides. This is a key point if one considers the prior lack of knowledge of their methylation status (82).

\section{Methylation-Sensitive Single-Strand Conformation Analysis}

Single-stranded conformational polymorphism (SSCP) analyses were reported several years ago in the broad context of detecting single-base polymorphisms as a means of resolving PCR products that differed by no more than a few 
nucleotides (77). Recently, Bianco et al. (8) adapted this technique to the study of methylation changes in specific DNA regions. They proposed combining bisulfite modification of the DNA with SSCP in a new method that they called methylation-sensitive single-strand conformation analysis (MS-SCCA). However, the same method has also been called bisulfite-PCR-SSCP (62).

Bisulfite modification of DNA generates accurate sequence disparities between methylated and unmethylated alleles, which can be resolved by SSCP (Figure 5). Methylcytosine detection using conventional SSCP requires the PCR amplification of the DNA fragments of interest, denaturation of the double-stranded product, followed by non-denaturing slab gel electrophoresis and detection via silver staining by standard methods.

MS-SSCA also yields semi-quantitative data. In particular, when one analyzes mixtures of methylated and unmethylated DNA of a known ratio, the relative intensities of the bands correlate with the relative degree of methylation of the original sequence. However, despite the great sensitivity [e.g., successful methylation analysis on microdissected paraffin-embedded tissues (7)] and rapidity of the method, the resolution for detecting single-base changes in a DNA fragment usually requires at least $10 \%$ of the population to show the alteration. Nevertheless, this is no longer a widespread problem because the modification of DNA normally involves several base changes in a fragment, which implies that the efficiency of detection may, in fact, reach almost $100 \%$.

In addition to classical non-denaturing slab gel electrophoresis, HPCE techniques can be considered an alternative approach to resolving PCR polymorphisms produced after bisulfite modification of the DNA (Figure 1) (90). This option has several advantages over the classical method, such as the simultaneous separation of alleles, use of non-denaturing gel, and automated means that allow sequential analyses of a large number of samples. Moreover, the relative percentage of methylation can be accurately quantified by calculating the area under methylated and unmethylated peaks directly on the electropherogram with an appropriate computer program (e.g., 32 Karat $^{\mathrm{TM}}$ Software; Beckman Coulter Spain S.A., Madrid, Spain). Under these conditions, the correlation coefficient in recovery experiments is 0.9994. Although this is one of the most powerful approaches to the quantitative analysis of the DNA methylation status of a defined DNA region, unfortunately, there are currently no reliable preparative facilities available.

\section{OTHER METHYLATION- DEPENDENT STRATEGIES NOT BASED ON BISULFITE}

Methylation-specific modification of DNA can be achieved by the use of hydrazine and permanganate. Hydrazine can react with $\mathrm{C}$ and $\mathrm{T}$ but not with methylcytosine (16), whereas permanganate reacts with methylcytosine and $\mathrm{T}$ but not with $\mathrm{C}$ (35). Both can react with ssDNA, but hydrazine can also react with dsDNA.

Hydrazine and permanganate-modified nucleotides can be removed with piperidine and detected by a number of sequencing methods such as ligationmediated PCR (93). The major drawback of both approaches is their poor sensitivity because, even under optimal conditions, usually at least $2 \mu \mathrm{g}$ DNA are required (65). Furthermore, at least $10 \%-20 \%$ of the population should display a certain alteration to be detected by these methods (81).

Low sensitivity and resolution in both methods, as well as the fact that sequencing methods are extremely labor-intensive, explain why hydrazine and permanganate are only occasionally used to check data obtained by the bisulfite-modification technique.

\section{HOW TO FIND NEW METHYLATION HOT SPOTS}

Classical DNA methylation research helps to investigate the methylation status of cytosines that occur in known (or partially known) DNA sequences. However, alternative ways of investigating genome-wide methylation by searching for as yet unidentified spots have been developed. All of these methods rely on the distinctive proper- 
ties of the $\mathrm{CpG}$ islands to find new methylated sequences in the genome.

The restriction landmark genomic scanning (RLGS) (49) technique is one of the earliest ways reported for genome-wide, methylation-specific searching (56). DNA is radioactively labeled at methylation-specific cleavage sites and then size-fractionated in 1-D. The products are then digested with any restriction endonuclease that is specific for high-frequency targets. Fragments are then separated in 2-D, which yields several scattered methylation-related hot spots. The location and strength of a spot reveal its locus and the copy number of the corresponding restriction site. This approach led to the discovery of several $\mathrm{CpG}$ islands of which there was no previous sequence knowledge $(52,56)$.

Gonzalgo et al. (43) described another suitable tool for screening the genome for regions that display altered patterns of DNA methylation. The method, termed methylation-sensitive arbitrarily primed PCR, is a simple DNA fingerprinting technique that relies on arbitrarily primed PCR amplification, followed by digestion with restriction isoschizomers. Strain-specific arrays of DNA fragments are generated by PCR amplification using arbitrary oligonucleotides to prime DNA synthesis from genomic sites that accidentally or roughly match. Usually, two cycles of PCR are performed under low-stringency conditions, followed by PCR at high stringency with specific primers. DNA amplified in this manner is digested with a couple of methylation-sensitive isoschizomers, and fragments displaying differential methylation patterns are cloned and used as probes for Southern blot analysis to corroborate the differential methylation of such DNA regions.

Another approach is called $\mathrm{CpG}$ island amplification (94). DNA is digested with restriction isoschizomers, and the restriction products are PCR-amplified after end-adaptor ligation. Al- though methylated $\mathrm{CpG}$ islands are selectively amplified, the cloning of truly CpG-rich DNA regions is frequently a laborious task.

Another original approach to isolate methylated $\mathrm{CpG}$-rich regions has recently been described (86). This method employs the affinity chromatography (20) of a fragment of the methyl-CpG binding domain of $\mathrm{MeCP} 2$ to purify methylated $\mathrm{CpG}$-rich fragments from mixtures obtained by digestion with methylation-specific restriction endonucleases. Fragments of interest are then cloned into a $\lambda$ Zap II vector (Stratagene, La Jolla, CA, USA), and the fragments that are mostly rich in $\mathrm{CpG}$ dinucleotides are isolated by the segregation of partially melted molecules in polyacrylamide gels that contain a linear gradient of chemical denaturant. Despite the advantages of this approach, the specificity of the methylated DNA binding column needs to be improved for it to be a first-class method. 
Undoubtedly, one of the most effective means of genome-wide searching for $\mathrm{CpG}$ islands is the use of the novel $\mathrm{CpG}$ island arrays technology. Huang et al. (53) proposed an array-based method, termed differential methylation hybridization, which allows the simultaneous determination of the methylation rate of greater than $276 \mathrm{CpG}$ island loci. $\mathrm{CpG}$ island library is obtained as previously described by Cross et al. (20), and the DNA fragments are gridded on highdensity arrays. Genomic DNA from the tissues of interest is digested with MseI, which yields a large number of fragments that contain intact $\mathrm{CpG}$ islands. Half of the subtracted DNA is then digested with methylation-sensitive endonuclease Bst $\mathrm{UI}$, whose sequence target occurs frequently within $\mathrm{CpG}$ islands. The digestion products are used as templates for linker PCR. Unmethylated targets are differentiated from methylated targets since the former are cut and no PCR products are obtained, while the latter can be amplified by linker PCR. Resulting oligonucleotides, termed pre-treated products, are used as probes for screening hypermethylated sequences within the $\mathrm{CpG}$ island library. Differential methylation hybridization has been applied to the screening of $\mathrm{CpG}$ methylation in cancer using $\mathrm{CpG}$ arrays of 300 and 1104 targets, respectively. Therefore, differential methylation hybridization can be used as a sophisticated screening tool for selecting putative DNA fragments susceptible to analysis in greater depth by other more specific methods. A modification of this method for the study of DNA methylation in cancer is the methylation-specific oligonucleotide microarray (39). After bisulfite treatment and PCR amplification, products are array-hybridized. Methylation-specific oligonucleotide microarrays are designed to detect methylation at specific nucleotide positions. Quantitative differences can be obtained by fluorescence detection.

\section{SUMMARY}

In contrast to genetic mutations, DNA methylation alters gene expression without DNA base changes. Currently, DNA methylation can be studied using a great variety of experimental techniques, involving a multidisciplinary perspective on the DNA methylation status. One approach is the quantification of the overall degree of DNA methylation. This can be accomplished by high-performance separation techniques, by enzymatic/chemical means, and even by in situ hybridization using antibodies antimethylcytosine. To analyze the DNA methylation status of a particular DNA sequence in depth, methylation-sensitive restriction endonucleases are commonly used. In addition, once bisulfite modification of the DNA has been accomplished, it is possible to obtain quantitative or semi-quantitative data regarding allele-specific methylation. Finally, several innovative techniques have been developed to investigate new, previously unknown methylation hot spots within the whole genome. Future steps toward automation and multi-assay arrays will allow large numbers of samples to be checked simultaneously.

\section{ACKNOWLEDGMENTS}

We thank Dr. Esteban Ballestar for helpful discussion. This work was supported by I+D+I Project SAF grant no. 2001-0059 and The International Rett Syndrome Association.

\section{REFERENCES}

1.Abrams, E.S., S.E. Murdaugh, and L.S. Lerman. 1990. Comprehensive detection of single base changes in human genomic DNA using denaturing gradient gel electrophoresis and a GC clamp. Genomics 7:463-475.

2.Adouard, V., R. Dante, A. Niveleau, E. Delain, B. Revet, and M. Ehrlich. 1985. The accessibility of 5-methylcytosine to specific antibodies in double-stranded DNA of Xanthomonas phage XP12. Eur. J. Biochem. 152:115121.

3.Annan, R.S., G.M. Kresbach, R.W. Giese, and P. Vouros. 1989. Trace detection of modified DNA bases via moving-belt liquid chromatography-mass spectrometry using electrophoric derivatization and negative chemical ionization. J. Chromatogr. 465:285-296.

4.Barbin, A., C. Montpellier, N. Kokalj-Vokac, A. Gibaud, A. Niveleau, B. Malfoy, B. Dutrillaux, and C.A. Bourgeois. 1994. New sites of methylcytosine-rich DNA detected on metaphase chromosomes. Hum. Genet. 94:684-692.

5.Baumer, A., U. Wiedemann, M. Hergersberg, and A. Schinzel. 2001. A novel MSP/ DHPLC method for the investigation of the methylation status of imprinted genes enables the molecular detection of low cell mosaicisms.
Hum. Mutat. 17:423-430.

6.Bensaada, M., H. Kiefer, G. Tachdjian, J.M. Lapierre, V. Cacheux, A. Niveleau, and P. Metezeau. 1998. Altered patterns of DNA methylation on chromosomes from leukemia cell lines: identification of 5-methylcytosines by indirect immunodetection. Cancer Genet. Cytogenet. 103:101-109.

7.Bian, Y.S., P. Yan, M.C. Osterheld, C. Fontolliet, and J. Benhattar. 2001. Promoter methylation analysis on microdissected paraffin-embedded tissues using bisulfite treatment and PCR-SSCP. BioTechniques 30:66-72.

8.Bianco, T., D. Hussey, and A. Dobrovic. 1999. Methylation-sensitive, single-strand conformation analysis (MS-SSCA): a rapid method to screen for and analyze methylation. Hum. Mutat. 14:289-293

9.Bigger, C.H., K. Murray, and N.E. Murray. 1973. Recognition sequence of a restriction enzyme. Nat. New Biol. 244:7-10.

10.Bird, A.P. 1986. CpG-rich islands and the function of DNA methylation. Nature 321:209213.

11.Bourc'his, D., D. Le Bourhis, D. Patin, A. Niveleau, P. Comizzoli, J. Renard, and E. Viegas-Pequignot. 2001. Delayed and incomplete reprogramming of chromosome methylation patterns in bovine cloned embryos. Curr. Biol. 11:1542-1546.

12.Busslinger, M., E. deBoer, S. Wright, F.G. Grosveld, and R.A. Flavell. 1983. The sequence GGCmCGG is resistant to $M s p$ I cleavage. Nucleic Acids Res. 11:3559-3569.

13.Butkus, V., L. Petrauskiene, Z. Maneliene, S. Klimasauskas, V. Laucys, and A. Janulaitis. 1987. Cleavage of methylated CCCGGG sequences containing either N4-methylcytosine or 5-methylcytosine with MspI, HpaII, SmaI, $\mathrm{XmaI}$ and $\mathrm{Cfr}$ 9I restriction endonucleases. $\mathrm{Nu}-$ cleic Acids Res. 15:7091-7102.

14.Catania, J., B.C. Keenan, G.P. Margison, and D.S. Fairweather. 1987. Determination of 5-methylcytosine by acid hydrolysis of DNA with hydrofluoric acid. Anal. Biochem. 167: 347-351.

15.Cedar, H., A. Solage, G. Glaser, and A. Razin. 1979. Direct detection of methylated cytosine in DNA by use of the restriction enzyme MspI. Nucleic Acids Res. 6:2125-2132.

16.Church, G.M. and W. Gilbert. 1985. The genomic sequencing technique. Prog. Clin. Biol. Res. 177:17-21.

17.Clark, S.J., J. Harrison, C.L. Paul, and M. Frommer. 1994. High sensitivity mapping of methylated cytosines. Nucleic Acids Res. 22:2990-2997.

18.Costello, J.F. and C. Plass. 2001. Methylation matters. J. Med. Genet. 38:285-303.

19.Cravo, M., R. Pinto, P. Fidalgo, P. Chaves, L. Gloria, C. Nobre-Leitao, and M.F. Costa. 1996. Global DNA hypomethylation occurs in the early stages of intestinal type gastric carcinoma. Gut 39:434-438.

20.Cross, S.H., J.A. Charlton, X. Nan, and A.P. Bird. 1994. Purification of $\mathrm{CpG}$ islands using a methylated DNA binding column. Nat. Genet. 6:236-244

21.de Capoa, A., F. Menendez, I. Poggesi, P. Giancotti, C. Grappelli, M.R. Marotta, M. Di Leandro, C. Reynaud, et al. 1996. Cytological evidence for 5-azacytidine-induced demeth- 
ylation of the heterochromatic regions of human chromosomes. Chromosome Res. 4: 271-276.

22.Diaz-Sala, C., M. Rey, A. Boronat, R. Besford, and R. Rodriguez. 1995. Variations in the DNA methylation and polypeptide patterns of adult hazel (corylus avellana L.) associated with sequential in vitro subcultures. Plant Cell Rep. 15:218-221.

23.Duthie, S.J., S. Narayanan, S. Blum, L. Pirie, and G.M. Brand. 2000. Folate deficiency in vitro induces uracil misincorporation and DNA hypomethylation and inhibits DNA excision repair in immortalized normal human colon epithelial cells. Nutr. Cancer 37:245-251.

24.Eads, C.A., K.D. Danenberg, K. Kawakami, L.B. Saltz, C. Blake, D. Shibata, P.V. Danenberg, and P.W. Laird. 2000. MethyLight: a high-throughput assay to measure DNA methylation. Nucleic Acids Res. 28:E32.

25.Ehrlich, M., M.A. Gama-Sosa, L.H. Huang, R.M. Midgett, K.C. Kuo, R.A. McCune, and C. Gehrke. 1982. Amount and distribution of 5-methylcytosine in human DNA from different types of tissues of cells. Nucleic Acids Res. 10:2709-2721.

26.Ehrlich, M. and K.C. Ehrlich. 1993. Effect of DNA methylation on the binding of vertebrate and plant proteins to DNA. EXS 64:145-168.

27.Eick, D., H.J. Fritz, and W. Doerfler. 1983. Quantitative determination of 5-methylcytosine in DNA by reverse-phase high-performance liquid chromatography. Anal. Biochem. 135: 165-171.

28.Esteller, M., S.R. Hamilton, P.C. Burger, S.B. Baylin, and J.G. Herman. 1999. Inactivation of the DNA repair gene O6-methylguanineDNA methyltransferase by promoter hypermethylation is a common event in primary human neoplasia. Cancer Res. 59:793-797.

29.Esteller, M., J. Garcia-Foncillas, E. Andion, S.N. Goodman, O.F. Hidalgo, V. Vanaclocha, S.B. Baylin, and J.G. Herman. 2000. Inactivation of the DNA-repair gene MGMT and the clinical response of gliomas to alkylating agents. N. Engl. J. Med. 343:1350-1354.

30.Esteller, M., A. Sparks, M. Toyota, M. Sanchez-Cespedes, G. Capella, M.A. Peinado, S. Gonzalez, G. Tarafa, et al. 2000. Analysis of adenomatous polyposis coli promoter hypermethylation in human cancer. Cancer Res. 60:4366-4371.

31.Esteller, M., P.G. Corn, S.B. Baylin, and J.G. Herman. 2001. A gene hypermethylation profile of human cancer. Cancer Res. 61:32253229.

32.Esteller, M., M.F. Fraga, M. Zhou-Guo, J. Garcia-Foncillas, A.K. Godwin, J. Trojan, I. Hedenfalk, C. Vaurs-Barrihre, et al. 2001. Aberrant CpG-island methylation profile and 5-methylcytosine DNA content in hereditary human cancer mimics sporadic tumorigenesis. Hum. Mol. Genet. 10:3001-3007.

33.Fraga, M.F., R. Rodriguez, and M.J. Canal. 2000. Rapid quantification of DNA methylation by high performance capillary electrophoresis. Electrophoresis 21:2990-2994.

34.Fraga, M.F., M.L. Centeno, A.E. Valdés, P. Moncaleán, M.J. Canal, and R. Rodriguez. 2000. Genomic DNA methylation and polyamines levels as key processes in plant aging: applications for clonal multiplication of mature
Pinus radiata trees, p. 495-506. In E. Ritter and S. Espinel (Eds.), Applications of Biotechnology to Forest Genetics. A.F. Albundia, Vitoria.

35.Fritzsche, E., H. Hayatsu, G.L. Igloi, S. Iida, and H. Kossel. 1987. The use of permanganate as a sequencing reagent for identification of 5methylcytosine residues in DNA. Nucleic Acids Res. 15:5517-5528.

36.Furuichi, Y., Y. Wataya, H. Hayatsu, and T. Ukita. 1970. Chemical modification of tRNATyr-yeast with bisulfite. A new method to modify isopentenyladenosine residue. Biochem. Biophys. Res. Commun. 41:1185-1191.

37.Galm, O., M. Rountree, E. Bachman, K.-W. Jair, S.B. Baylin, and J. Herman. 2001. Enzymatic regional methylation assay: a novel method to quantify regional $\mathrm{CpG}$ methylation density. Genome Res. 12:153-157.

38.Gama-Sosa, M.A., R.M. Midgett, V.A. Slagel, S. Githens, K.C. Kuo, C.W. Gehrke, and M. Ehrlich. 1983. Tissue-specific differences in DNA methylation in various mammals. Biochim. Biophys. Acta 740:212-219.

39.Gitan, R.S., H. Shi, C.M. Chen, P.S. Yan, and T.H. Huang. 2002. Methylation-specific oligonucleotide microarray: a new potential for high-throughput methylation analysis. Genome Res. 12:158-164.

40.Gloria, L., M. Cravo, A. Pinto, L.S. de Sousa, P. Chaves, C.N. Leitao, M. Quina, F.C. Mira, et al. 1996. DNA hypomethylation and proliferative activity are increased in the rectal mucosa of patients with long-standing ulcerative colitis. Cancer 78:2300-2306.

41.Goessl, C., M. Muller, R. Heicappell, H. Krause, and K. Miller. 2001. DNA-based detection of prostate cancer in blood, urine, and ejaculates. Ann. NY Acad. Sci. 945:51-58.

42.Gonzalgo, M.L. and P.A. Jones. 1997. Rapid quantitation of methylation differences at specific sites using methylation-sensitive single nucleotide primer extension (MS-SNuPE). Nucleic Acids Res. 25:2529-2531.

43.Gonzalgo, M.L., G. Liang, C.H. Spruck, III, J.M. Zingg, W.M. Rideout, III, and P.A. Jones. 1997. Identification and characterization of differentially methylated regions of genomic DNA by methylation-sensitive arbitrarily primed PCR. Cancer Res. 57:594-599.

44.Gowher, H., O. Leismann, and A. Jeltsch. 2000. DNA of Drosophila melanogaster contains 5-methylcytosine. EMBO J. 19:69186923.

45.Grigg, G. and S. Clark. 1994. Sequencing 5methylcytosine residues in genomic DNA. Bioessays 16:431-436.

46.Gruenbaum, Y., T. Naveh-Many, H. Cedar, and A. Razin. 1981. Sequence specificity of methylation in higher plant DNA. Nature 292:860-862.

47.Grunau, C., S.J. Clark, and A. Rosenthal. 2001. Bisulfite genomic sequencing: systematic investigation of critical experimental parameters. Nucleic Acids Res. 29:E65.

48.Harrison, J., C. Stirzaker, and S.J. Clark. 1998. Cytosines adjacent to methylated CpG sites can be partially resistant to conversion in genomic bisulfite sequencing leading to methylation artifacts. Anal. Biochem. 264:129-132.

49.Hatada, I., Y. Hayashizaki, S. Hirotsune, H. Komatsubara, and T. Mukai. 1991. A genomic scanning method for higher organisms using restriction sites as landmarks. Proc. Natl. Acad. Sci. USA 88:9523-9527.

50.Heiskanen, M., A.C. Syvanen, H. Siitari, S Laine, and A. Palotie. 1994. A novel method to quantitate methylation of specific genomic regions. PCR Methods Appl. 4:26-30.

51.Herman, J.G., J.R. Graff, S. Myohanen, B.D. Nelkin, and S.B. Baylin. 1996. Methylationspecific PCR: a novel PCR assay for methylation status of $\mathrm{CpG}$ islands. Proc. Natl. Acad. Sci. USA 93:9821-9826.

52.Hirotsune, S., K. Hirose, H. Kataoka, J. Kuromitsu, Y. Furuichi, M. Muramatsu, Y. Matsuda, and Y. Hayashizaki. 1994. Spot mapping on the standard profile of restriction landmark genomic scanning (RLGS) of sorted chromosome 20 using methylation-insensitive enzyme. Genomics 24:593-596.

53.Huang, T.H., M.R. Perry, and D.E. Laux. 1999. Methylation profiling of CpG islands in human breast cancer cells. Hum. Mol. Genet. 8:459-470.

54.Jackson, P., D. Millar, E. Kingsley, G. Yardley, K. Ow, S. Clark, and P.J. Russell. 2000. Methylation of a $\mathrm{CpG}$ island within the promoter region of the KAI1 metastasis suppressor gene is not responsible for down-regulation of KAI1 expression in invasive cancers or cancer cell lines. Cancer Lett. 157:169-176.

55.Jones, P.L. and A.P. Wolffe. 1999. Relationships between chromatin organization and DNA methylation in determining gene expression. Semin. Cancer Biol. 9:339-347.

56.Kawai, J., S. Hirotsune, K. Hirose, S. Fushiki, S. Watanabe, and Y. Hayashizaki. 1993. Methylation profiles of genomic DNA of mouse developmental brain detected by restriction landmark genomic scanning (RLGS) method. Nucleic Acids Res. 21:5604-5608

57.Kosaki, K., M.J. McGinniss, A.N. Veraksa, W.J. McGinnis, and K.L. Jones. 1997. Prader-Willi and Angelman syndromes: diagnosis with a bisulfite-treated methylation-specific PCR method. Am. J. Med. Genet. 73:308-313.

58.Kuo, K.C., R.A. McCune, C.W. Gehrke, R. Midgett, and M. Ehrlich. 1980. Quantitative reversed-phase high performance liquid chromatographic determination of major and modified deoxyribonucleosides in DNA. Nucleic Acids Res. 8:4763-4776

59.Kupper, D., M. Reuter, A. Meisel, and D.H. Kruger. 1997. Reliable detection of DNA CpG methylation profiles by the isoschizomers MspI/HpaII using oligonucleotide stimulators. BioTechniques 23:843-847.

60.Kutueva, L.I., V.V. Ashapkin, and B.F. Vanyushin. 1996. The methylation pattern of a cytosine DNA-methyltransferase gene in Arabidopsis thaliana plants. Biochem. Mol. Biol. Int 40:347-353.

61.Leonard, S.A., S.C. Wong, and J.W. Nyce. 1993. Quantitation of 5-methylcytosine by onedimensional high-performance thin-layer chromatography. J. Chromatogr. 645:189-192.

62.Maekawa, M., K. Sugano, H. Kashiwabara, M. Ushiama, S. Fujita, M. Yoshimori, and T. Kakizoe. 1999. DNA methylation analysis using bisulfite treatment and PCR-single-strand conformation polymorphism in colorectal cancer showing microsatellite instability. Biochem. Biophys. Res. Commun. 262:671-676.

63.Maniatis, T., E.F. Fritsch, and J. Sambrook. 
1982. Molecular Cloning: A Laboratory Manual. CSH Laboratory Press, Cold Spring Harbor, NY.

64.McClelland, M., M. Nelson, and E. Raschke. 1994. Effect of site-specific modification on restriction endonucleases and DNA modification methyltransferases. Nucleic Acids Res. 22: 3640-3659.

65.McGrew, M.J. and N. Rosenthal. 1993. Quantitation of genomic methylation using ligation-mediated PCR. BioTechniques 15:722729.

66.Melki, J.R., P.C. Vincent, and S.J. Clark. 1999. Concurrent DNA hypermethylation of multiple genes in acute myeloid leukemia. Cancer Res. 59:3730-3740.

67.Miller, O.J., W. Schnedl, J. Allen, and B.F Erlanger. 1974. 5-methylcytosine localized in mammalian constitutive heterochromatin. Nature 251:636-637.

68.Miniou, P., M. Jeanpierre, V. Blanquet, V. Sibella, D. Bonneau, C. Herbelin, A. Fischer, A. Niveleau, et al. 1994. Abnormal methylation pattern in constitutive and facultative (X inactive chromosome) heterochromatin of ICF patients. Hum. Mol. Genet. 3:2093-2102.

69.Mizugaki, M., K. Itoh, T. Yamaguchi, S. Ishiwata, T. Hishinuma, S. Nozaki, and N. Ishida. 1996. Preparation of a monoclonal antibody specific for 5-methyl-2'- deoxycytidine and its application for the detection of DNA methylation levels in human peripheral blood cells. Biol. Pharm. Bull. 19:1537-1540.

70.Montpellier, C., C.A. Burgeois, N. KokaljVokac, M. Muleris, A. Niveleau, C. Reynaud, A. Gibaud, B. Malfoy, et al. 1994. Detection of methylcytosine-rich heterochromatin on banded chromosomes. Application to cells with various status of DNA methylation. Cancer Genet. Cytogenet. 78:87-93

71.Norwood, C.B., E. Jackim, and S. Cheer 1993. DNA adduct research with capillary electrophoresis. Anal. Biochem. 213:194-199.

72.Nuovo, G.J., T.W. Plaia, S.A. Belinsky, S.B. Baylin, and J.G. Herman. 1999. In situ detection of the hypermethylation-induced inactivation of the p16 gene as an early event in oncogenesis. Proc. Natl. Acad. Sci. USA 96:12754-12759.

73.Oakeley, E.J., A. Podesta, and J.P. Jost. 1997. Developmental changes in DNA methylation of the two tobacco pollen nuclei during maturation. Proc. Natl. Acad. Sci. USA 94:1172111725.

74.Oakeley, E.J., F. Schmitt, and J.P. Jost. 1999. Quantification of 5-methylcytosine in DNA by the chloroacetaldehyde reaction. BioTechniques 27:744-752

75.Paul, C.L. and S.J. Clark. 1996. Cytosine methylation: quantitation by automated genomic sequencing and GENESCAN analysis. BioTechniques 21:126-133.

76.Piyathilake, C.J., A.R. Frost, W.C. Bell, D. Oelschlager, H. Weiss, G.L. Johanning, A. Niveleau, D.C. Heimburger, et al. 2001. Altered global methylation of DNA: an epigenetic difference in susceptibility for lung cancer is associated with its progression. Hum. Pathol. 32:856-862.

77.Poduslo, S.E., M. Dean, U. Kolch, and S.J. O'Brien. 1991. Detecting high-resolution polymorphisms in human coding loci by com- bining PCR and single-strand conformation polymorphism (SSCP) analysis. Am. J. Hum. Genet. 49:106-111.

78.Quivy, J.P. and P.B. Becker. 1994. Direct dideoxy sequencing of genomic DNA by ligation-mediated PCR. BioTechniques 16:238241.

79.Radlinska, M. and K. Skowronek. 1998. Novel procedure for the detection of 5-methylcytosine. Acta Microbiol. Pol. 47:327-334.

80.Raizis, A.M., F. Schmitt, and J.P. Jost. 1995. A bisulfite method of 5-methylcytosine mapping that minimizes template degradation. Anal. Biochem. 226:161-166.

81.Rein, T., D.A. Natale, U. Gartner, M. Niggemann, M.L. DePamphilis, and H. Zorbas. 1997. Absence of an unusual "densely methylated island" at the hamster dhfr ori- $\beta$. J. Biol. Chem. 272:10021-10029.

82.Rein, T., M.L. DePamphilis, and H. Zorbas. 1998. Identifying 5-methylcytosine and related modifications in DNA genomes. Nucleic Acids Res. 26:2255-2264.

83.Saluz, H. and J.P. Jost. 1993. Major techniques to study DNA methylation. EXS 64:1126.

84.Shapiro, R., V. DiFate, and M. Welcher. 1974. Deamination of cytosine derivatives by bisulfite. Mechanism of the reaction. J. Am. Chem. Soc. 96:206-212.

85.Sharma, M., R. Jain, E. Ionescu, and H.K. Slocum. 1995. Capillary electrophoretic separation and laser-induced fluorescence detection of the major DNA adducts of cisplatin and carboplatin. Anal. Biochem. 228:307-311.

86.Shiraishi, M., Y.H. Chuu, and T. Sekiya. 1999. Isolation of DNA fragments associated with methylated $\mathrm{CpG}$ islands in human adenocarcinomas of the lung using a methylated DNA binding column and denaturing gradient gel electrophoresis. Proc. Natl. Acad. Sci. USA 96:2913-2918.

87.Singer-Sam, J., M. Grant, J.M. LeBon, K. Okuyama, V. Chapman, M. Monk, and A.D. Riggs. 1990. Use of a HpaII-polymerase chain reaction assay to study DNA methylation in the Pgk-1 CpG island of mouse embryos at the time of X-chromosome inactivation. Mol. Cell. Biol. 10:4987-4989.

88.Singer-Sam, J., J.M. LeBon, R.L. Tanguay, and A.D. Riggs. 1990. A quantitative HpaIIPCR assay to measure methylation of DNA from a small number of cells. Nucleic Acids Res. 18:687.

89.Stirzaker, C., D.S. Millar, C.L. Paul, P.M. Warnecke, J. Harrison, P.C. Vincent, M. Frommer, and S.J. Clark. 1997. Extensive DNA methylation spanning the $\mathrm{Rb}$ promoter in retinoblastoma tumors. Cancer Res. 57:22292237.

90.Suzuki, H., F. Itoh, M. Toyota, T. Kikuchi, H. Kakiuchi, Y. Hinoda, and K. Imai. 2000. Quantitative DNA methylation analysis by fluorescent polymerase chain reaction singlestrand conformation polymorphism using an automated DNA sequencer. Electrophoresis 21:904-908.

91.Tan, W.G., T.J. Carnelley, P. Murphy, H. Wang, J. Lee, S. Barker, M. Weinfeld, and X.C. Le. 2001. Detection of DNA adducts of benzo[a]pyrene using immunoelectrophoresis with laser-induced fluorescence. Analysis of
A549 cells. J. Chromatogr. A 924:377-386.

92.Tasheva, E.S. and D.J. Roufa. 1994. Densely methylated DNA islands in mammalian chromosomal replication origins. Mol. Cell. Biol. 14:5636-5644.

93.Thomassin, H., E.J. Oakeley, and T. Grange. 1999. Identification of 5-methylcytosine in complex genomes. Methods 19:465-475

94.Toyota, M., C. Ho, N. Ahuja, K.W. Jair, Q. Li, M. Ohe-Toyota, S.B. Baylin, and J.P. Issa. 1999. Identification of differentially methylated sequences in colorectal cancer by methylated $\mathrm{CpG}$ island amplification. Cancer Res. 59:2307-2312.

95.Turk, P.W. and S.A. Weitzman. 1995. Free radical DNA adduct 8-OH-deoxyguanosine affects activity of $H p a I I$ and $M s p I$ restriction endonucleases. Free Radic. Res. 23:255-258.

96.Uchida, T., H. Ohashi, E. Aoki, Y. Nakahara, T. Hotta, T. Murate, H. Saito, and T. Kinoshita. 2000. Clonality analysis by methylation-specific PCR for the human androgen-receptor gene (HUMARA-MSP). Leukemia 14:207-212.

97.Veilleux, C., J. Bernardino, A. Gibaud, A. Niveleau, B. Malfoy, B. Dutrillaux, and C.A. Bourgeois. 1995. [Changes in methylation of tumor cells: a new in situ quantitative approach on interphase nuclei and chromosomes]. Bull. Cancer 82:939-945.

98. Wagner, I. and I. Capesius. 1981. Determination of 5-methylcytosine from plant DNA by high-performance liquid chromatography. Biochim. Biophys. Acta 654:52-56

99.Wolffe, A.P., P.L. Jones, and P.A. Wade. 1999. DNA demethylation. Proc. Natl. Acad. Sci. USA 96:5894-5896.

100.Worth, C.C., O.J. Schmitz, H.C. Kliem, and M. Wiessler. 2000. Synthesis of fluorescently labeled alkylated DNA adduct standards and separation by capillary electrophoresis. Electrophoresis 21:2086-2091.

101.Wu, J., J.P. Issa, J. Herman, D.E. Bassett, Jr., B.D. Nelkin, and S.B. Baylin. 1993. Expression of an exogenous eukaryotic DNA methyltransferase gene induces transformation of NIH 3 T3 cells. Proc. Natl. Acad. Sci. USA 90:8891-8895.

102.Xiong, Z. and P.W. Laird. 1997. COBRA: a sensitive and quantitative DNA methylation assay. Nucleic Acids Res. 25:2532-2534.

103.Zhou, Y., J.M. Magill, R.J. Newton, and C. Magill. 1997. Use of a single sequencing termination reaction to distinguish between cytosine and 5-methylcytosine in bisulfite-modified DNA. BioTechniques 22:850-854.

Address correspondence to:

Dr. Manel Esteller

Cancer Epigenetics Laboratory

Program of Molecular Pathology

Centro Nacional de Investigaciones

Oncológicas (CNIO)

C/Melchor Fernández Almagro, no. 3. E-28029,

Madrid, Spain

e-mail:mesteller@cnio.es 